\title{
Кластерный анализ данных химического микрокартирования трабекулярной ткани при первичной открытоугольной глаукоме
}

М. В. Кравчик ${ }^{1,2}$, И. А. Новиков ${ }^{1}$, Т. Е. Борисенко', А. М. Суббот, к. М. н. ${ }^{1}$, С. Ю. Петров, д. м. Н. ${ }^{1}$

УДК: 51-76

\begin{abstract}
Проанализирована возможность использования кластерного анализа для оценки структурно-функциональной организации биологического объекта. Для количественного описания клеточных процессов выбрана фильтрующая (трабекулярная) ткань глаза при нестабилизированной первичной открытоугольной глаукоме (ПОУГ) у пациентов, использующих максимально возможную гипотензивную терапию. Методом химического микроанализа на базе сканирующего электронного микроскопа (СэМ) получены данные о распределении химических элементов в ткани. На основе глобального индекса Морана, описывающего степень пространственной группировки серы $\left(I_{S}\right)$ и фосфора $\left(I_{p}\right)$ на поверхности блока анализируемой ткани, предложен характеризующий клеточные процессы индекс потери целевой метаболической активности $\left(\mathrm{I}_{\mathrm{L}}\right)$. Установлена связь между $\mathrm{I}_{L}$ и визуально наблюдаемым различием в организации структурных элементов трабекулярной ткани при ПОУГ. Прослежена корреляция между структурно-функциональным статусом трабекулярной ткани по индексу $\mathrm{I}_{L}$ и внутриглазным давлением (ВГД) на максимальной гипотензивной терапии.
\end{abstract}

Ключевые слова: кластерный анализ, индекс Морана, элементный состав, энергодисперсионная спектроскопия, первичная открытоугольная глаукома, трабекулярная ткань

The possibility of using cluster analysis to assess the structural and functional organization of a biological object is analyzed. For a quantitative description of cellular processes, filtering (trabecular) eye tissue was selected for unstabilized primary open-angle glaucoma (POAG) in patients using the maximum possible hypotensive therapy. By chemical microanalysis based on a scanning electron microscope (SEM), data were obtained on the distribution of chemical elements in tissue. Based on the global Moran index, which describes the degree of spatial grouping of sulfur $\left(I_{S}\right)$ and phosphorus $\left(I_{p}\right)$ on the surface of the analyzed tissue block, an index of target metabolic activity loss $\left(\mathrm{I}_{\mathrm{L}}\right)$ characterizing cellular processes is proposed. A connection was established between $I_{L}$ and the visually observed difference in the organization of structural elements of trabecular tissue in POAG. A correlation was observed between the structural and functional status of trabecular tissue according to the $\mathrm{I}_{\mathrm{L}}$ index and intraocular pressure (IOP) on the maximum hypotensive therapy.

Keywords: cluster analysis, Moran's I index, elemental composition, energy-dispersive X-ray spectroscopy, primary open-angle glaucoma, trabecular meshwork

Статья получена 26.02.2020 Принята к публикации 15.06.2020

ФГБНу «нии глазных болезней», Москва.

2 kravchik.mv@gmail.com. 


\section{Введение}

Патологические процессы в биологическом объекте зачастую вызываются и всегда сопровождаются нарушением его организации. Даже минимальные функциональные отклонения не могут возникнуть и исчезнуть, не отразившись в соответствующих изменениях на структурном уровне [1]. Информация о структуре и пространственной организации биологической ткани может быть использована в качестве ключевого показателя ее функциональных возможностей, в том числе при различных патологических процессах.

Одним из заболеваний с доказанными структурно-функциональными отклонениями является глаукома. Это состояние сопряжено с постоянным или периодическим повышением ВГД, которое приводит к развитию атрофии зрительного нерва, сопровождающейся типичными функциональными нарушениями зрения [2]. В структуре трабекулярной ткани дренажной зоны глаза возникают аномалии, которые определяются не только геометрической деформацией тканей, но и накоплением патологического для этой зоны материала. Отложение привносимых в ткань трабекулы веществ приводит к запуску "порочного круга", так как усугубляет ретенцию внутриглазной жидкости (ВГЖ) и способствует дальнейшему повышению ВГД [3]. В свою очередь, направленная на утилизацию осаждаемых патологических депозитов функциональная активность клеток трабекулы должна иметь большое значение в стабилизации течения заболевания и компенсации патологического процесса.

Сложная архитектоника трабекулярной сети затрудняет интерпретацию возможных ее функциональных изменений при патологии на клеточном и тканевом уровнях организации. На настоящий момент большинство исследований функциональных изменений клеток и тканей направлено на получение только количественных характеристик, отражающих их общую дисфункцию, без объективного описания пространственной структурнофункциональной картины на должном доказательном уровне. При этом современные методы на базе световой и электронной микроскопии позволяют получать пространственные данные о распределении того или иного маркера, характеризующего активность и взаимную позицию элементов в ткани. К сожалению, даже полученные количественные данные об изменчивости признака в пространстве, как правило, служат только для составления субъективной описательной картины и должным образом не обрабатываются математически. Поэтому весьма очевидно возникает вопрос о необходимости нового объективного метода анализа структуры нативного биологического объекта, обобщающего наблюдаемую картину при различных процессах и позволяющего дать количественную оценку структурнофункциональным изменениям, которые происходят в его объеме. Представляется перспективным найти показатель, который характеризует пространственную активность клеток в биологической ткани, в том числе и при экстремальных (патологических) состояниях, сопровождающихся нарушением тканевой функции.

Для решения поставленной задачи мы обратились к кластерному анализу как к инструменту пространственной статистики, позволяющему количественно описать распределение отдельных элементов. Кластерный анализ (или кластеризация) - это задача разбиения некоторого множества на группы, называемые кластерами. Внутри каждой группы должны оказаться "похожие» компоненты. С помощью кластерного анализа возможно сгруппировать элементы единого объекта по сходству значений, характеризующих их признаков.

Один из инструментов кластерного анализа глобальный индекс Морана - отражает пространственную автокорреляцию между взаимным расположением элементов и сходством их значений по некоторому показателю. Вычисление пространственной автокорреляции при помощи данного инструмента основано одновременно на данных о положении анализируемых элементов и значениях присущих им признаков. Индекс Морана при этом показывает, имеется ли в распределении элементов кластеры, или компоненты объекта распределены разбросанно или случайно [4]. Несмотря на то, что этот универсальный инструмент можно применить в оценке пространственного распределения составных элементов различных биологических объектов на разных уровнях организации живого, на текущий момент примеры использования таких вычислений в биологии и медицине зачастую ограничены лишь эпидемиологическими задачами, где распределение компонентов оценивается на популяционном уровне [5-7].

Для объективного описания нарушений в биологическом объекте с измененным структурнофункциональным статусом были взяты образцы трабекулярной ткани пациентов с нестабилизированным течением глаукомы. Несмотря на проводимую максимально возможную гипотензивную терапию, у этой категории больных в результате 
офтальмологического обследования выявляется ухудшение в состоянии поля зрения - ведущего функционального показателя на органном уровне. В нашей работе предпринята попытка количественного описания функциональной несостоятельности на более низком (тканевом) уровне организации.

Для решения поставленной задачи проведен анализ ткани дренажной зоны, патологическое изменение которой препятствует снижению ВГд до индивидуальных приемлемых значений. В качестве первичных данных для описания структурнофункциональной организации ткани (позиции активных клеток и патологических отложений) использовали результаты химического микрокартирования.

\section{Материалы и методы}

Для исследования отбирали пациентов сплошным методом. В комплекс предоперационных обследований входили стандартные офтальмологические: визометрия, биомикроскопия, офтальмоскопия, статическая компьютерная периметрия, определение роговично-компенсированного ВГД. Критерием включения в исследуемую группу был установленный диагноз ПОУГ второй и третьей стадий на максимально возможной гипотензивной терапии. Оценку стадии глаукомы проводили по классификации А. П. Нестерова. В качестве клинического показателя, отражающего функциональное состояние ткани дренажной зоны глаза, был выбран уровень ВГД, диапазон которого составил 13,3-32,6 мм рт. ст. (медиана 24,95 мм рт. ст.). Медианное значение ВГД использовано для разделения пациентов на две группы: в первую вошли 14 пациентов с ВГД < 25 мм рт. ст., во вторую 14 пациентов с ВГД $\geq 25$ мм рт. ст.

Ткань для исследования забирали непосредственно в ходе непроникающей антиглаукомной операции (глубокой склерэктомии с наружной трабекулэктомией). Дальнейшее изучение образцов проводили на микроскопе EVO LS10 (Zeiss, Германия). Для навигации по образцу и выбора области поверхность всех эксплантов визуализировали с помощью детектора обратнорассеянных электронов (BSD) в режиме низкого вакуума (EP, 70 Па) при ускоряющем напряжении 21,5 кB и токе на образце 420 пА. Для получения информации о пространственном распределении химических элементов проводили химическое микрокартирование поверхности каждого образца при помощи энергодисперсионного рентгеновского спектрометра (ЭДС)
Oxford X-Max-50 (Oxford, Великобритания). Сила тока на образце 490-520 пА, выдержка - 3000 с, разрешение - 512×384 пикс. Применяя эту методику, удалось оценить распределение углерода (C), азота $(\mathrm{N})$, кислорода $(\mathrm{O})$, натрия $(\mathrm{Na})$, магния $(\mathrm{Mg})$, алюминия (Al), кремния (Si), фосфора (P), серы (S), хлора (Cl), калия (K), кальция (Ca), железа (Fe) на поверхности трабекулярной ткани.

Для решения поставленной в работе задачи количественного описания функциональной несостоятельности ткани для анализа были выбраны паттерны распределения Р и S в предположении, что при изменении функционального статуса на поверхности анализируемого блока ткани происходят изменения в пространственном распределении как P, так и S. При этом Р выбран в качестве маркера позиции метаболически активных клеток, как компонент остатков фосфорной кислоты, в присутствии которой происходят все энергозависимые процессы. Сера, как компонент привносимых с током ВГЖ веществ, задана в качестве маркера патологического дебриса.

Необходимо учесть, что получаемая на СЭМ двумерная карта распределения химических элементов представляет собой совокупность данных о химическом составе поверхности и некоторой подлежащей области "легкой" матрицы, где возможно возбуждение характеристического рентгеновского излучения электронами пучка.

Вычисления проводили в реальной прямоугольной декартовой системе координат на плоскости, соответствующей карте распределения относительных концентраций химических элементов. Расстояние между точками захвата качественных данных о химическом составе поверхности составило 126,9 нм. В качестве показателя интенсивности (C) использовали получаемое путем вычитания сигнала фона количество импульсов характеристического излучения от соответствующего элемента в каждой точке карты (режим TrueMap, программная оболочка Aztec, Oxford Instruments inc., Великобритания). Для вычисления степени группировки в пространстве фосфора (P) и серы (S) исходные данные микрокартирования преобразовывали в формат $x, y, C_{P}$ и $C_{S}$, где $x$ и y-координаты по соответствующим осям в условной прямоугольной системе координат, $C_{P}$ и $C_{S}$ - интенсивности излучения Р и $S$ соответственно в каждой (с координатами $x, y)$ точке пространства. Степень группировки Р и S в пространстве, а также степень этой связи рассчитывали с помощью аппарата пространственной статистики. Для этого по каждому образцу формировали матрицу пространственных весов, затем 
по Р и S вычисляли глобальный индекс Морана (Moran's I) по формуле:

$$
I=\frac{n \sum_{i=1}^{n} \sum_{j=i}^{n} \omega_{i j}\left(C_{i}-\bar{C}\right)\left(C_{j}-\bar{C}\right)}{\left[\sum_{i=1}^{n} \sum_{j=i}^{n} \omega_{i j}\right]\left[\sum_{i=1}^{n}\left(C_{i}-\bar{C}\right)^{2}\right]},
$$

где $n$ - количество точек, в которых проводили измерения; $\omega_{i j}$ - расстояние между $і$-й и j-й точкой в условных единицах; $C_{\mathrm{i}}$ - интенсивность сигнала в $і$-й точке анализируемого пространства (количество импульсов от изучаемого элемента); $\overline{\mathrm{C}}$ - выборочное среднее значение интенсивности сигнала от изучаемого элемента по всем точкам.

Автоматизированную статистическую обработку проводили с помощью программы GeoDa. При этом все оцениваемые показатели по умолчанию не относили к нормальному закону даже в случае прохождения теста на нормальность распределения, что связано как с качественным метрологическим классом химического анализа, так и с ограниченным базовым распределением глобального индекса морана $(-1 ; 1)$.

\section{Вычисление индекса потери целевой метаболической \\ активности}

Предварительный визуальный анализ изображений поверхности ткани выявил, что распределения $S$ и Р в образце могут иметь некоторое сходство, либо отличаться в сторону как большей, так и меньшей рассеянности. Причем отмечено, что данный эффект не зависит от стадии заболевания. Так, на поверхности трабекулярной ткани одного пациента с третьей стадией ПОУГ (рис. 1) паттерны распределения S (рис. 1в) и $\mathrm{P}$ (рис. 1б) согласованы друг
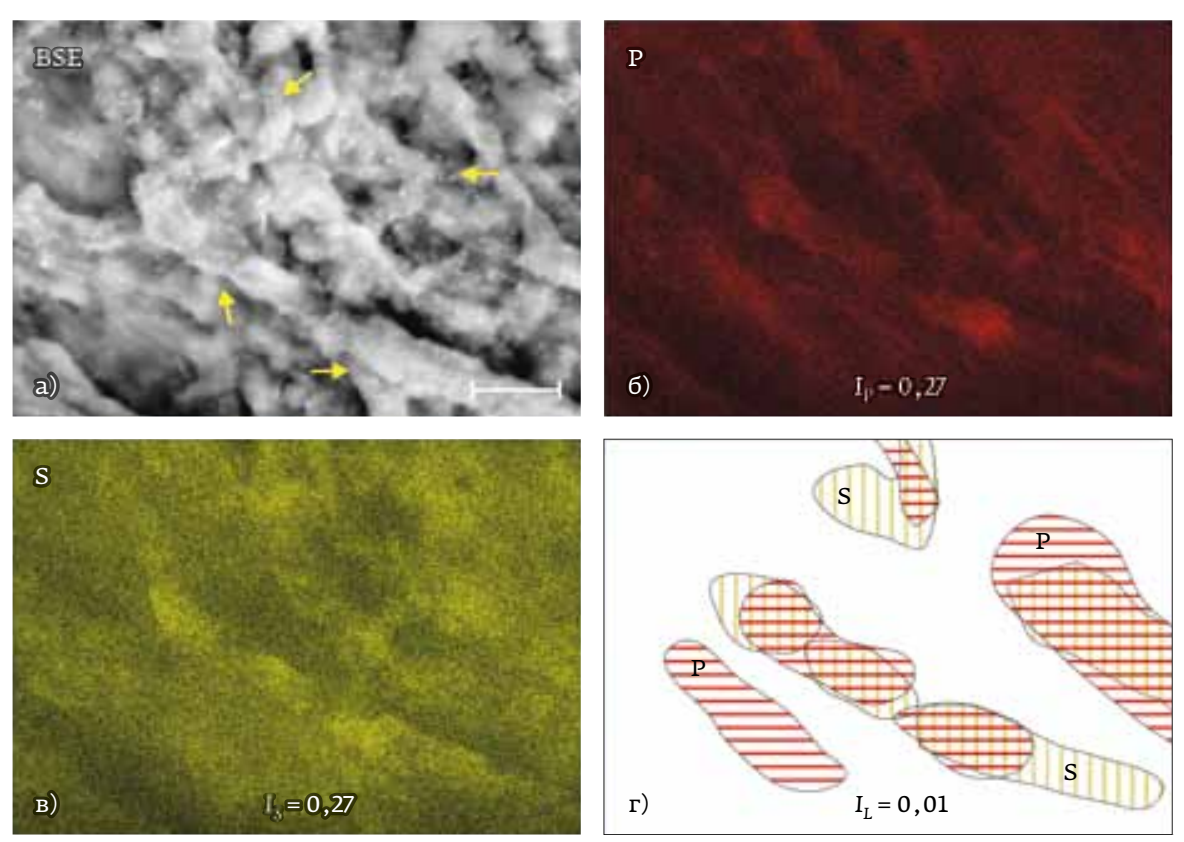

Puс. 1. Изображение поверхности трабекулярной ткани с относительно сохранным киеточным ответом при ПОУГ III cm., полученное на СЭМ, масштаб 10 мкм: а - изображение в обратнорассеянных электронах, стрелками указаны агрегаты пигмента; 6 - распределение Р по данным ЭДС; в - распределение S по данным ЭДС; г - схема взаимного расположения максимумов Р (красная горизонтальная штриховка) и S (желтая вертикальная штриховка)
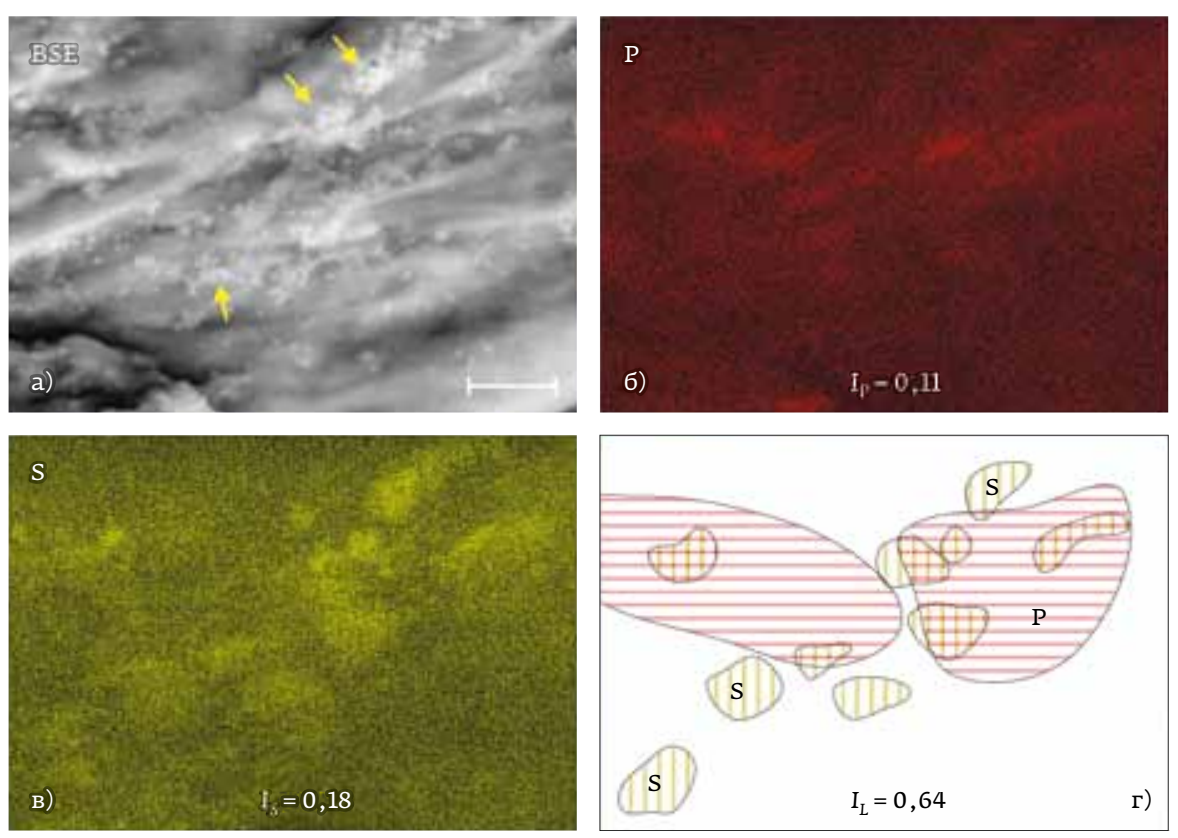

Puc. 2. Изображение поверхности трабекулярной ткани с относительной потерей целевой метаболической активности клеток при ПОУг III cm., полученное на СЭМ, масштаб 10 мкм: а - изображение в обратнорассеянных электронах, стрелками указаны агрегаты пигмента; б - распределение Р по данным ЭДС; в - распределение S по данным ЭДС; г - схема взаимного расположения максимумов Р (красная горизонтальная штриховка) и S (желтая вертикальная штриховка) 
с другом, а на поверхности образца, взятого у другого больного с той же стадией ПОУГ (рис. 2), локальное скопление S (рис. 2в) не согласовано с более рассеянным распределением P (рис. 2б). На иллюстрациях рис. 1 и 2 для распределения $S$ и Р на соответствующих картах даны значения глобального индекса Морана $\left(\mathrm{I}_{\mathrm{P}}\right.$ и $\left.\mathrm{I}_{S}\right)$, на схеме взаимного распределения приведена величина индекса потери целевой клеточной активности $\mathrm{I}_{\mathrm{L}}$.

Чтобы объяснить полученные экспериментальные результаты, сделано следующее предположение. Когда клеточная активность направлена на утилизацию серосодержащего патологического материала, клетки в объеме ткани группируются сходно с паттерном целевой мишени - серосодержащими веществами, которые становятся объектом воздействия при изучаемой патологии. При эффективной клеточной деятельности степени сгруппированности маркера метаболической активности клеток (P) и мишени этой активности (S) должны сближаться. При потере целевой активности будет появляться расхождение в кластерах этих двух элементов. Исходя из этого, на основе глобального индекса Морана, характеризующего степень пространственной сгруппированности $S\left(I_{S}\right)$ и $\mathrm{P}\left(\mathrm{I}_{\mathrm{P}}\right)$ на поверхности блока анализируемой ткани, можно оценить отношение $I_{S} / I_{p}$, которое при эффективной клеточной деятельности должно стремиться к единице. Уменьшение отношения $I_{S} / I_{P}$, в свою очередь, отражает неэффективность клеточной деятельности, поэтому предложен количественный параметр индекс потери целевой метаболической активности $\left(\mathrm{I}_{\mathrm{L}}\right)$, рассчитываемый по формуле:

$$
I_{L}=\left|1-\left(I_{S} / I_{P}\right)\right|
$$

где $I_{S}$ и $I_{P}$ - глобальные индексы Морана для условной кластеризации в пространстве $S$ и $\mathrm{P}$ соответ- $^{-}$ ственно.

\section{Результаты}

На изображениях, полученных на электронном микроскопе в обратнорассеянных электронах (BSE) (рис. 1а и 2a), между пластинами трабекулярной ткани были обнаружены агрегаты связанных пигментных гранул (обозначены стрелками на рис. 1a и 2а). Последующее микрокартирование этих участков при помощи ЭДС показало, что связующее вещество является высокосернистым (локальные максимумы условной концентрации $S$ на рис. 1в и 2в соответствуют агрегатам пигментных гранул на рис. 1а и 2а).
Таким образом, именно пигментные агрегаты проявлялись в виде выраженных локальных максимумов содержания $S$ на поверхности трабекулярной ткани. Объективная сгруппированность $S$ в пространстве при этом - умеренная: вычисленный индекс Морана $\left(I_{S}\right)$ находился в диапазоне 0,01-0,47 (медиана 0,18). При этом значение $I_{S}$ в двух группах не отличалось по медиане. Так, в первой группе (пациенты с ВГД<25 мм рт. ст.) $\mathrm{I}_{S}$ находился в диапазоне $0,05-0,28$ (медиана 0,18 ). Во второй группе (пациенты с ВГД $\geq 25$ мм рт. ст.) $\mathrm{I}_{S}-0,01-0,49$ (медиана 0,18).

При химическом микрокартировании ткани дренажной зоны пациентов также была выявлена пространственная неоднородность в распределении Р (см. рис. 16 и 2б), а локальные максимумы условной концентрации Р соответствовали позиции клеток трабекулы на изображении, полученHом в BSE. Вычисленный для распределения Р индекс Морана $\left(\mathrm{I}_{\mathrm{P}}\right)$ находился в диапазоне 0,09-0,51 (медиана 0,19). Значение медианы $I_{P}$, как и в случае с $S$, мало отличалось в двух группах пациентов. В первой группе (пациенты с ВГД<25 мм рт. ст.) $\mathrm{I}_{\mathrm{P}}$ находился в диапазоне 0,09-0,51 (медиана 0,20). Во второй группе (пациенты с ВГД $\geq 25$ мм рт. ст.) $I_{P}-0,10-0,35$ (медиана 0,16). Итак, две группы пациентов характеризовались сходными медианными значениями в степени сгруппированности Р отдельно и $\mathrm{S}$ отдельно.

Был проведен анализ совместного изменения паттерна распределения Р и S (расчет $\mathrm{I}_{\mathrm{L}}$ ). Вычисленный индекс возрастал при увеличении визуально наблюдаемой диспропорциональности в распределении $\mathrm{S}$ и Р на поверхности анализируемой ткани. Так, на рис. 1 распределения локальных максимумов накопления Р и S соответствует друг другу, что иллюстрируется на схеме взаимного расположения локальных максимумов Р и S (рис. 1г), где области красной горизонтальной штриховки (максимум Р) систематически накладываются на области желтой вертикальной штриховки (максимум $S$ ), при этом $I_{L}=0,01$. На рис. 2 локальные максимумы накопления $\mathrm{P}$ и $S$ пространственно разобщены, при этом на схеме взаимного расположения локальных максимумов Р и $\mathrm{S}$ (рис. 2г) области красной горизонтальной штриховки (максимум Р) в большей, чем на рис. 1г, степени не совпадают с областью желтой вертикальной штриховки (максимум $S$ ), а $I_{L}$ принимает значение 0,64. $\mathrm{I}_{\mathrm{L}}$ для всех пациентов колебался в диапазоне 0,01-1,07 (медиана 0,56).

Также изменялось значение $I_{L}$ в различных группах пациентов, разделенных в зависимости от уровня ВГд. Обнаружено, что в первой группе 
(пациенты с ВГД<25 мм рт. ст.) $\mathrm{I}_{\mathrm{L}}$ находился в диапазоне 0,01-0,74 (медиана 0,29), а во второй группе (пациенты с ВГД 225 мм рт. ст.) был значимо выше: $\mathrm{I}_{\mathrm{L}}-0,28-1,07$ (медиана 0,72).

\section{Обсуждение}

По многочисленным данным световой и электронной микроскопии, биологическая ткань обладает сложной структурной иерархией. Ткань трабекулярного аппарата глаза, через который фильтруется ВГЖ, состоит из нескольких морфологически и функционально разнородных отделов, в той или иной степени обладающих регуляторными функциями по отношению к офтальмотонусу. Первым регулятором оттока ВГЖ являются клетки увеальной и корнеосклеральной части, обладающие фагоцитарной активностью. Затем жидкость проходит через юкстаканаликулярную часть, чьи клетки обладают и фибробластоподобными, и гладкомышечными признаками [8, 9]. Структурно-функциональная разнородность отделов трабекулярного аппарата зависит не только от их послойного расположения по отношению к другим тканям глаза, но также от такого фактора, как возраст организма. На культуре показано, что в “молодой" ткани преобладает макрофагальный элемент, доля которого по отношению к фибробластно-гладкомышечному уменьшается с увеличением возраста донора [10].

Таким образом, трабекулярная ткань характеризуется сложными взаимоотношениями составляющих ее различных клеточных элементов. Однако стоит отметить, что, несмотря на вариативность проявлений специализированной функциональной активности разных клеток дренажной зоны глаза, при патологии отмечают общее снижение их жизнеспособности. В литературе широко описаны структурно-метаболические дефекты клеток ткани трабекулярного аппарата при нарушении офтальмотонуса. К сожалению, в своем большинстве, наблюдения также носят субъективный описательный характер. А. В. Куроедов, анализируя дистрофические изменения трабекулы, отмечает уплотнения хроматина, фрагментацию ядра и митохондриальное клеточное истощение, коррелирующее со стадией глаукомы [11]. А. Изотти (A. Izotti) установлено значительное снижение числа клеток трабекулярной сети и количества митохондрий при ПОУГ [12]. В. Ю. Огородниковой выявлены изменения структуры митохондрий трабекулярной зоны у пациентов с ПОУГ, что, по мнению автора, может свидетельствовать о структурно-метаболических изменениях ткани при патологии [13].
В настоящем исследовании подвергались анализу образцы трабекулярной ткани пациентов с отсутствием стабилизации ПОУГ. При этом максимально возможная гипотензивная терапия, включающая вещества, которые частично блокируют продукцию ВГЖ, не приводила к снижению ВГД до приемлемого для данного пациента уровня. Выдвинуто предположение, согласно которому на фоне предельной терапии изменения в ткани трабекулярного аппарата максимально характеризуют ее функциональную несостоятельность, являющуюся, в свою очередь, одним из определяющих факторов динамики патологического процесса.

При относительной функциональной сохранности ткани патологические изменения, сопряженные с аккумуляцией аномальных веществ, вызывают активизацию энергозатратных клеточных механизмов. Эффективная компенсация сопровождается мобилизацией клеток, их структуризацией и увеличением степени клеточной организации. При процессах, направленных на компенсацию патологических изменений, степень организации клеток в ткани возрастает. Стоит отметить, что клеточные энергозависимые процессы в организме происходят в присутствии остатков фосфорной кислоты, ангидридные связи между которыми обладают большим запасом потенциальной энергии [14]. Это объясняет пространственное соответствие локальных максимумов условной концентрации Р позиции клеток (клеточных ядер) на поверхности анализируемой ткани, и именно присутствие Р в ткани можно рассматривать в качестве маркера активных клеток, а увеличение сгруппированности локальных максимумов Р - маркером активизации клеточной активности.

По нашим наблюдениям, осаждаемый в дренажной зоне патологический материал активно аккумулирует серу - при электронной микроскопии между пластинами трабекул выявлены пигментные агрегаты, "склеенные" между собой серосодержащим веществом. Неоднородная пространственная организация S в структуре нативного биологического образца, соответствующая участкам накопления патологического материала, позволила нам предположить, что серосодержащие соединения могут выступать в качестве маркера увеличения веществ, накапливаемых в дренажной зоне по ходу тока ВГЖ. Литературные данные согласуются с полученным результатом: S может включаться в структуру меланина, аккумулируемого в дренажной зоне глаза при глаукоме $[15,16]$. Также известно, что белковые молекулы и, возможно, иные соединения в составе патологических веществ, накапливающихся в углу 
передней камеры при глаукомном процессе, являются серосодержащими $[17,18]$.

Помимо описательного анализа визуальных данных, обсуждение которого приведено двумя абзацами выше, в нашем исследовании проведена попытка количественно охарактеризовать эффективную клеточную активность с применением заявленных маркеров описанных процессов (пространственного распределения $\mathrm{S}$ и $\mathrm{P}$ ) и методов пространственной статистики. При этом проводилась оценка согласованности изменений маркеров. Согласно нашим наблюдениям и вычислениям, наиболее эффективный клеточный метаболизм сопровождается скоординированным изменением степени пространственной организации $S$ и Р и сопряженными изменениями в степени их сгруппированности. При этом на образцах с визуальным сходством в группировании S и P (см. рис. 1) вычисленный с помощью кластерного анализа $\mathrm{I}_{\mathrm{L}}$ принимает минимальные значения.

Известно, что, помимо активизации компенсаторных процессов, результатом взаимодействия различных систем организма с патологическим фактором может быть утрата клеточных систем регуляции [19]. Ответ клеток может быть как эффективным, так и не адекватным происходящим в ткани изменениям. В нашем исследовании обнаружены пробы, где S и Р группировались не одинаково (см. рис. 2). Визуально выявленные различия в распределениях S и Р на поверхности различных образцов оценивались как относительная клеточная дисфункция, когда невозможна мобилизация клеток в качестве регуляторной системы, и клеточный метаболизм не столь эффективен по отношению к накопившемуся серосодержащему детриту. При этом вычисленный количественный параметр - $\mathrm{I}_{\mathrm{L}}$ - принимал максимальные значения.

Итак, с точки зрения статистики, при эффективной клеточной работе показатели пространственной автокорреляции $\mathrm{P}\left(\mathrm{I}_{\mathrm{S}}\right)$ и $\mathrm{S}\left(\mathrm{I}_{\mathrm{P}}\right)$ сближаются, а соотношение $I_{S} / I_{P}-$ стремится к единице. И напротив, дисрегуляция в системе клеточного ответа приводит к уменьшению этого соотношения, а IL возрастает при увеличении визуально регистрируемой диспропорции в распределении $S$ и Р на поверхности анализируемой ткани.

Ожидаемо, что при росте ВГд функциональная активность клеток дренажной зоны, лишенных физиологичного окружения, падает. Предполагается, что при изменении ВГД может меняться и вычисленный индекс как параметр утраты клеточной регуляции в ткани трабекулы. При проверке гипотезы пропорциональности $\mathrm{I}_{\mathrm{L}}$ системным функциональным

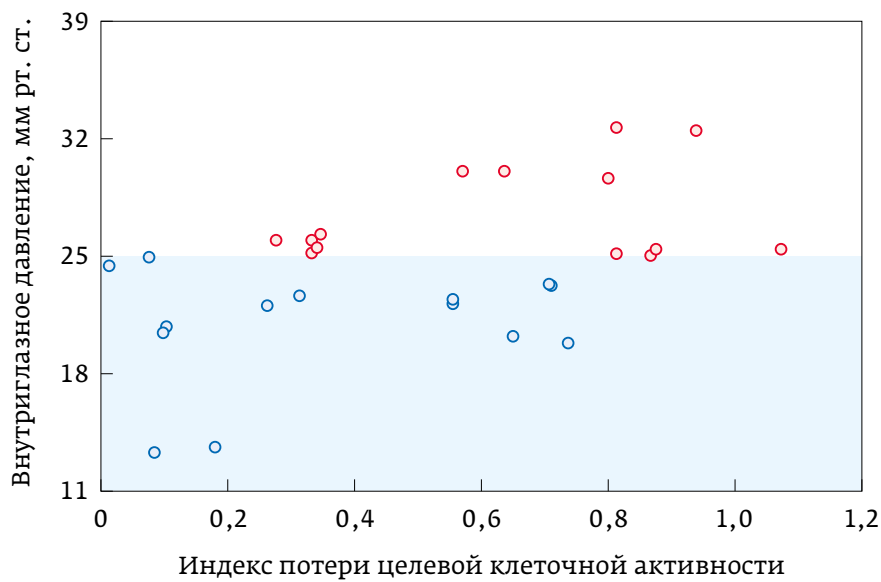

Puс. 3. Диаграмма распределения индекса потери целевой метаболической активности $\left(I_{L}\right)$ в зависимости от роговично-компенсированного ВГД

нарушениям (степень декомпенсации ВГд) выявлено, что в группе с высоким уровнем ВГд происходит увеличение индекса потери целевой метаболической активности: медианное значение $\mathrm{I}_{\mathrm{L}}$ увеличивается в несколько раз (0,29 - в первой группе, 0,72 - во второй). Визуально изменение $I_{L}$ в группах можно проследить на рис. 3, где данные пациентов с ВГД<25 мм рт. ст. и с ВГД $\geq 25$ мм рт. ст. группируются на голубом и белом фоне диаграммы соответственно.

\section{Заключение}

Впервые удалось продемонстрировать возможности аппарата пространственной статистики для оценки структурных связей в самом биологическом объекте. В качестве информации для кластерного анализа как метода пространственной статистики использованы данные о двумерном распределении функционально значимых химических элементов (S и P) на поверхности анализируемой биологической ткани. Рассчитан количественный показатель, характеризующий организацию целевых химических элементов в ткани. С учетом информации об участии Р в энергозатратных клеточных процессах и S - в аккумуляции патологических веществ в ткани трабекулы - удалось интерпретировать рассчитанный показатель $\left(\mathrm{I}_{\mathrm{L}}\right)$ с точки зрения успешной клеточной активности. Значение $I_{L}$ соотносилось и с данными о функциональной несостоятельности регуляторной системы клеточного ответа - уровнем ВГд при нестабилизированной глаукоме на фоне предельной гипотензивной терапии. Таким образом, впервые показаны возможности пространственной статистики 
МИР НЕФТЕПРОДУКТОВ

\section{Приглашаем авторов и рекламодателей к сотрудничеству!}
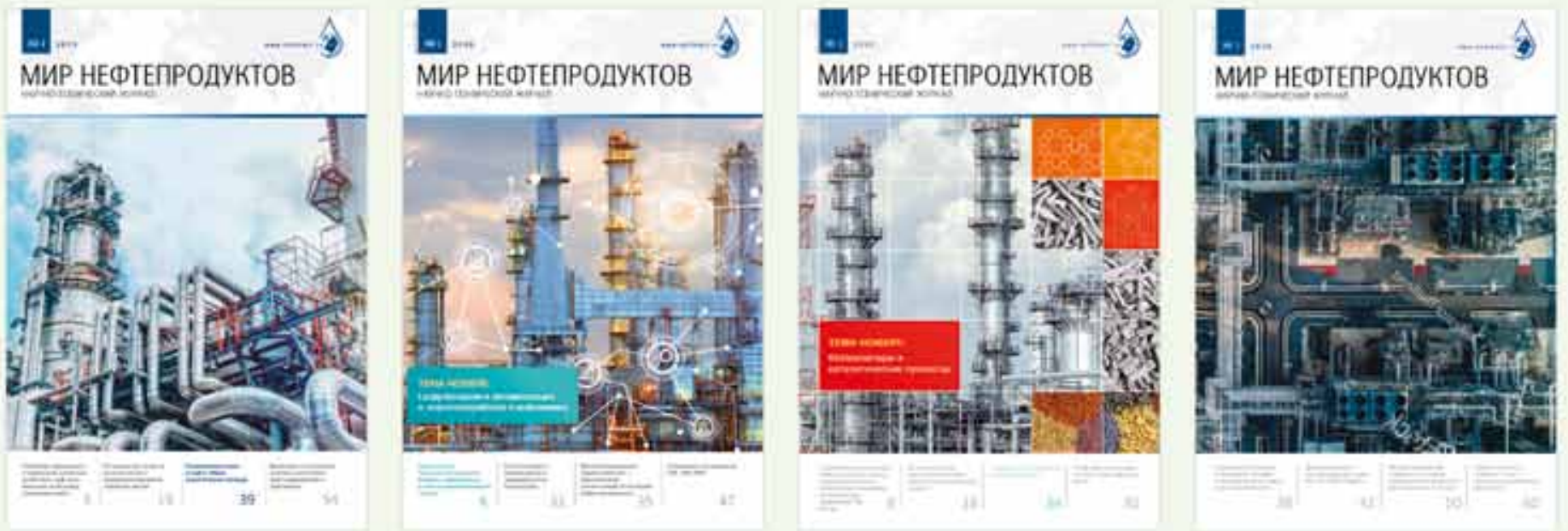

Основные рубрики журнала:

Химия и технология переработки нефти

Нефтехимия: технология, процессы

Аналитический контроль нефти и нефтепродуктов

Химмотология

Смазочные материалы и масла

Оборудование и приборы

Промышленная безопасность и экология

Автоматизация и операционная эффективность
Темы номеров на 2020 год:

Цифровизация и автоматизация

Катализаторы

Смазочные материалы и масла

Инновационные решения в технологиях нефтепереработки

Аналитический контроль нефти и нефтепродуктов Промышленная безопасность и экология

\section{Анонс свежего номера на сайте neftemir.ru}

Мир нефтепродуктов - ведущий отраспевой научно-технический журнал по нефтехимии, нефтепереработке, аналитическому и экологическому контролю

ISSN 2071-5951

Входит в перечень ВАK и Chemical Abstracts

Периодичность - 6 номеров в год + спец.выпуски

Объем - 64 полосы, полностью цветное издание

Тираж - 2000 экз. (бумажная и электронная версии)

Главный редактор - Капустин В. М. - д-р техн. наук, профессор. РГУ нефти и газа (НИУ) им. И. М. Губкина Подписной индекс єУрал-Прессз на 6 месяцев - 013408 на 12 месяцев - 013393

$10 \%$ скидка на годовую подписку в редакции от 4-х экземпляров при оформлении в 2020 г. Подписка возможна с любого месяца

\section{Контакты:}

Шеф-редактор:

Воскресенская Кристиана

chief@neftemir.ru

+7 (921) 449-66-00
Помощник шеф-редактора: Подписка:

Безель Марина

editor@neftemir.ru
Зырина Алёна

info@neftemir.ru

+7 (812) 313-54-14
Отраслевые мероприятия: Бербенцева Елена pr@neftemir.ru +7 (911) 848-14-79 
не только в отношении оценки структуры биологического объекта, но и анализа его функциональных особенностей: получен показатель, который соответствует не только визуально наблюдаемым структурным данным, но и сопутствующим им функциональным нарушениям.

Показатели, полученные на основе кластерного анализа, удобны для обработки всех типов качественной, количественной и полуколичественной информации, распределение которой в биологическом объекте можно оценить современными методами оптической и электронной микроскопии. Считаем весьма перспективным предложенный подход к оценке других биологических сложноорганизованных структур при различных патологических процессах.

\section{Литература}

1. Саркисов Д.С., Пальцев М.А., Хитров Н.К. Общая патология человека. М.: Медицина, 1997. 608 с.

2. Нестеров А.П. Глаукома. М.: Медицина, 1995. 256 с.

3. Егоров Е.А. Глаукома. Национальное руководство / Под ред. проф. Е. А. Егорова, проф. Ю. С. Астахова, проф. А. Г. Щуко. М.: ГЭОТАРМедиа, 2011. 280 c.

4. Moran P.A.P. Notes on continuous stochastic phenomena // Biometrika. 1950.V. 37. № 1-2. P. 17-23.

5. Carpenter T. Methods to investigate spatial and temporal clustering in veterinary epidemiology // Preventive veterinary medicine. 2001. V. 48. P. 303-320.

6. De la Rua-Domenech R., Mohammed H., Atwill E. R., Cummings J., Divers T., Summers B., DeLahunta A., Jackson C. Epidemiologic evidence for clustering of equine motor neuron disease in the United States // American journal of veterinary research. 1995. V. 56. № 11. P. 1433-1439.

7. Shaikh M.A., Malik N.A. Spatial Cluster Analysis Of New And Relapsed Cases Of Pulmonary Tuberculosis By District: Pakistan 2015 // Journal of Ayub Medical College, Abbottabad: JAMC. 2019. V. 31. № 2. P. 293-295.

8. Золотарев А.В. Микрохирургическая анатомия дренажной системы глаза. Самара, 2009. 72 с.

9. Stamer W.D., Clark A.F. The many faces of the trabecular meshwork cell // Exp Eye Res. 2017. V. 158. P. 112-123.

10. Kelley M.J., Rose A.Y., Keller K.E., Hessle H., Samples J. R., Acott T.S. Stem cells in the trabecular meshwork: present and future promises // Exp Eye Res. 2009. V. 88. № 4. P. 747-751.

11. Куроедов А.В., Огородникова В.Ю., Смирнова Е. А. Изменение митохондрий в клетках трабекулярной сети глаза больных первичной открытоугольной глаукомой // Офтальмология. 2011. Т. 8. № 2. C. 8-11.

12. Izzotti A., Sacca S.C., Longobardi M., Cartiglia C. Mitochondrial damage in the trabecular meshwork of patients with glaucoma // Arch Ophthalmol. 2010. V. 128. No. № 6. P. 724-730.

13. Огородникова В.Ю., Егоров Е.А., Куроедов А.В., Маркитантова Ю. В., Петров А.Н. Результаты исследования апоптоза клеток дренажной зоны методом иммунохимического анализа у пациентов с продвинутыми стадиями глаукомы // РМЖ. Клиническая офтальмология. 2012. Т. 13. № 3. С. 82-85.

14. Biological inorganic chemistry: structure and reactivity / Bertini I. Sausalito, Calif.: University Science Books, 2007. XXV. 739 p.

15. Ito S., Novellino E., Chioccara F., Misuraca G., Prota G. Co-polymerization of dopa and cysteinyldopa in melanogenesis in vitro // Experientia. 1980. V. 36. No. 7. P. 822-823.

16. Wielgus A. R., Sarna T. Melanin in human irides of different color and age of donors // Pigment Cell Res. 2005. V. 18. № 6. P. 454-864.
17. Ritch R., Schlotzer-Schrehardt U. Exfoliation syndrome // Surv Ophthalmol. 2001. V. 45. No. 4. P. 265-315.

18. Vranka J. A., Kelley M.J., Acott T.S., Keller K.E. Extracellular matrix in the trabecular meshwork: intraocular pressure regulation and dysregulation in glaucoma // Exp Eye Res. 2015. V. 133. P. 112-125.

19. Шанин В.Ю. Патофизиология критических состояний. СПб: ЭЛБИ-Спб, 2003. 436 с.

\section{References}

1. Sarkisov D.S., Pal'tsev M. A., Khitrov N. K. General Human Pathology. Moscow, Meditsina Publ., 1997. 608 p.

2. Nesterov A.P. Glaucoma. Moscow, Meditsina Publ., 1995. $256 \mathrm{p}$.

3. Egorov E. A. Glaucoma. National Leadership. Ed. prof. E. A. Egorov, prof. Yu.S. Astakhov, prof. A.G.Schuko. Moscow, GEOTARMedia Publ., 2011. 280 p.

4. Moran P.A.P. Notes on Continuous Stochastic Phenomena // Biometrika 1950. V. 37. No. 1-2. P. 17-23.

5. Carpenter T. Methods to Investigate Spatial and Temporal Clustering in Veterinary Epidemiology // Preventive veterinary medicine. 2001. V. 48. P. 303-320.

6. De la Rua-Domenech R., Mohammed H., Atwill E. R., Cummings J., Divers T., Summers B., DeLahunta A., Jackson C. Epidemiologic Evidence for Clustering of Equine Motor Neuron Disease in the United States // American journal of veterinary research. 1995, V. 56. No. 11. P. 1433-1439.

7. Shaikh M.A., Malik N.A. Spatial Cluster Analysis of New And Relapsed Cases Of Pulmonary Tuberculosis By District: Pakistan 2015 // Journal of Ayub Medical College, Abbottabad: JAMC, 2019. V. 31. No. 2. P. 293-295.

8. Zolotarev A.V. Microsurgical Anatomy of the Drainage System of the Eye, Samara, 2009. 72 p.

9. Stamer W.D., Clark A.F. The Many Faces of the Trabecular Meshwork Cell // Experimental Eye Research 2017. V. 158. P. 112-123.

10. Kelley M. J., Rose A.Y., Keller K.E., Hessle H., Samples J. R., Acott T.S. Stem Cells in the Trabecular Meshwork: Present and Future Promises // Experimental Eye Research. 2009. V. 88. No. 4. P. 747-751.

11. Kuroedov A.V., Ogorodnikova V.Yu., Smirnova E. A. Changes in Mitochondria in the Cells of the Trabecular Meshwork of the Eye of Patients with Primary Open Angle Glaucoma // Oftal'mologiya Ophthalmology. 2011. V. 8. No. 2. P. 8-11.

12. Izzotti A., Sacca S. C., Longobardi M., Cartiglia C. Mitochondrial Damage in the Trabecular Meshwork of Patients with Glaucoma // Archives of Ophthalmology 2010. V. 128. No. 6. P. 724-730.

13. Ogorodnikova V.Yu., Egorov E.A., Kuroedov A.V., Markitantova Yu. V., Petrov A.N. The Results of the Study of Apoptosis of the Cells of the Drainage Zone by the Method of Immunochemical Analysis in Patients with Advanced Stages of Claucoma // Russkii meditsinskii zhurnal. Klinicheskaya oftal'mologiya - Russian medical journal. Clinical Ophthalmology 2012. V. 13. No. 3. P. 82-85.

14. Bertini I. Biological Inorganic Chemistry: Structure and Reactivity / California, University Science Books Publ., 2007.

15. Ito S., Novellino E., Chioccara F., Misuraca G., Prota G. Co-polymerization of Dopa and Cysteinyldopa in Melanogenesis in Vitro // Experientia 1980. V. 36. No. 7. P. 822-823.

16. Wielgus A. R., Sarna T. Melanin in Human Irides of Different Color and Age of Donors // Pigment Cell Research 2005. V. 18. No. 6. P. 454-864.

17. Ritch R., Schlotzer-Schrehardt U. Exfoliation Syndrome // Survey of Ophthalmology 2001. V. 45. No. 4. P. 265-315.

18. Vranka J.A., Kelley M.J., Acott T.S., Keller K.E. Extracellular Matrix in the Trabecular Meshwork: Intraocular Pressure Regulation and Dysregulation in Glaucoma // Experimental Eye Research. 2015. V. 133. P. 112-125.

19. Shanin V.Yu. Pathophysiology of Critical Illnes / Saint Petersburg, ELBI-Spb Publ., 2003. 436 p. 


\section{6-9 ОКТЯБРЯ 2020}
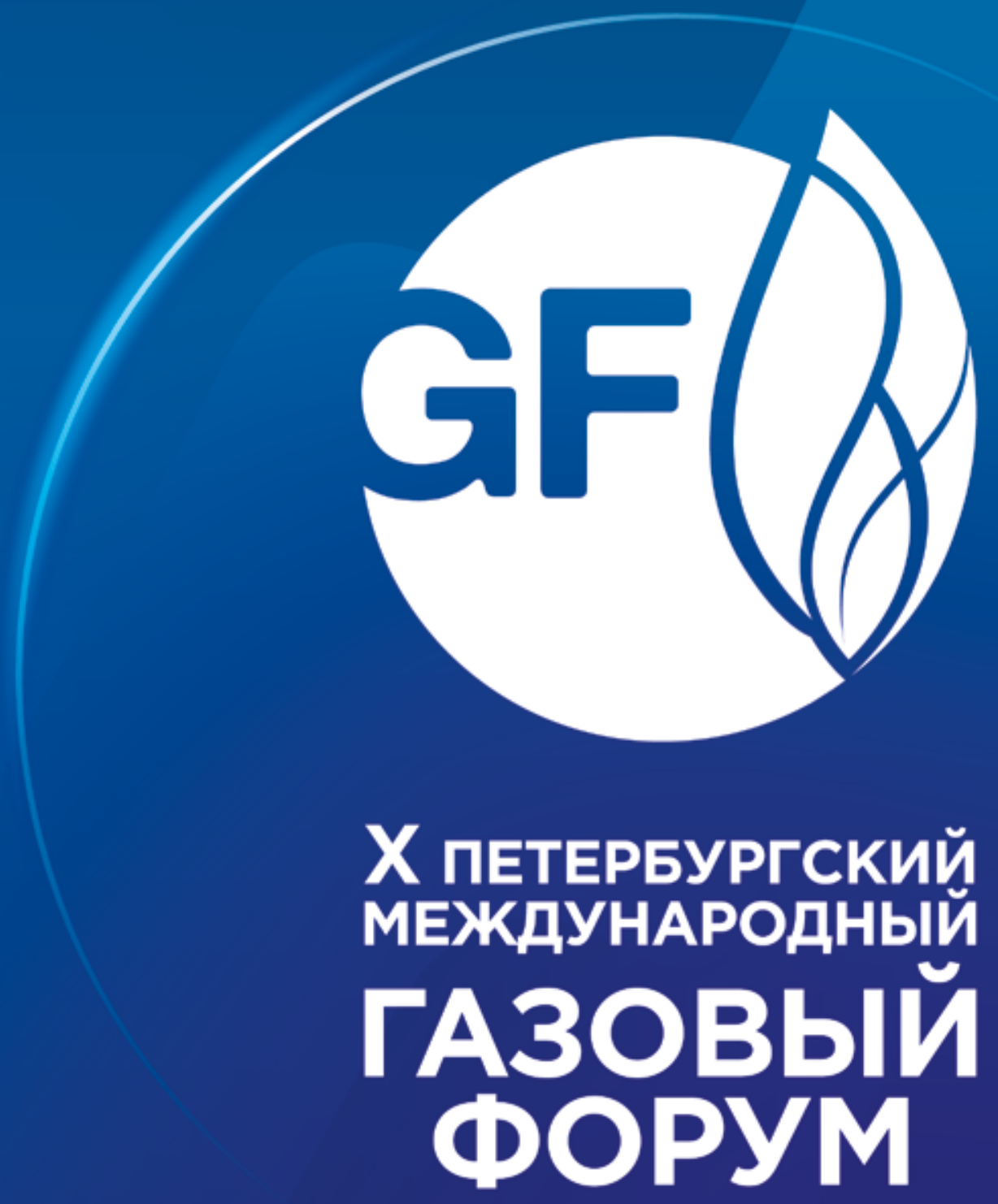

ПРИЗНАННАЯ ПЛОЩАДКА ДЛЯ ДИСКУССИИ О РАЗВИТИИ МИРОВОЙ ГАЗОВОЙ ОТРАСЛИ

s.

А. минпромторг

А России

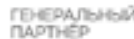

OPТАНИЗАТОР

EXPOFORUM

10

КОНГРЕССНО-ВЫСТАВОЧНЫЙ ЦЕНТР

ЭКСПОФОРУМ

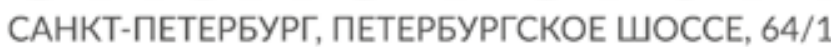

TAPTHEPA

uni

OMV

G ГАзпром

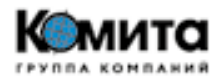

